\title{
ESTUDO TRIGONOMÉTRICO PARA BOCAIS DE LANÇA DE BOF COM MULTIPLOS JATOS *
}

\author{
Breno Totti Maia ${ }^{1}$ \\ Fabrício Silveira Garajau² \\ Felipe Silveira Batista ${ }^{3}$ \\ Willian dos Reis Lima ${ }^{4}$ \\ Marcelo de Souza Lima Guerra ${ }^{5}$ \\ Roberto Parreiras Tavares ${ }^{6}$
}

\section{Resumo}

O presente trabalho teve por objetivo uma análise de parâmetros geométricos de bicos de lança em operação e uma extrapolação para situações futuras. Foram determinadas as principais relações trigonométricas e, a partir disso, verificada a possibilidade de "coalescência". Os principais resultados mostram que círculo primitivo dos bocais (PCD) não tem qualquer influência nas relações trigonométricas do bocal, limitado pelo ângulo de saída divergente. Bicos com até 04 furos e pequeno ângulo com a vertical podem promover a coalescência e bicos com mais furos afastam essa possibilidade assim como a relação entre número de furos e ângulo entre dois bocais adjacentes. O presente trabalho mostrou uma importante ferramenta para determinação de condições para desenvolvimento de novos bicos de lança.

Palavras-chave: BOF; Bico de lança; Ângulo entre bocais; Adjacentes; PCD; Coalescência; Ângulo dos bocais com vertical; Número de bocais.

\section{TRIGONOMETRIC STUDY FOR BOF LANCE TIP ANGLES WITH MULTI JETS}

\begin{abstract}
In the present work, an analysis of geometric parameters of tip nozzles in operation was developed and extrapolations for futures situations were proposed. The main trigonometric relationships to evaluate the possibility of jet coalescence were determined. The results showed that the Primary Circle Diameter (PCD) is not affected only by the geometry of the nozzle, tips with up to 04 (four) nozzles and small angle with the vertical can promote coalescence and tips with more nozzles than four reduce this possibility. This work also presents a relationship between number of nozzles and angle between two adjacent nozzles. An important tool to determining conditions for development of new tips lance is proposed.

Keywords: BOF; Tip lance; Angle between adjacent nozzles; PCD; Coalescence; Angle nozzles with vertical; Number nozzles.

1 Eng. Metalurgista, Doutor Pesquisador da Lumar Metals, Sócio da ABM. Belo Horizonte, MG, Brasil;

2 Eng.Mecânico e Pesquisador da Lumar Metals, sócio da ABM. Ipatinga, MG,Brasil;

3 Eng.Mecânico e Pesquisador da Lumar Metals, sócio da ABM. Ipatinga, MG,Brasil;

4 Eng.Mecânico e Analista da Lumar Metals, sócio da ABM. Ipatinga, MG,Brasil;

5 Eng.Mecânico e Analista da Lumar Metals, sócio da ABM. Ipatinga, MG,Brasil;

6 Sócio da ABM; Engenheiro Metalurgista; Professor Doutor do Departamento de Engenharia Metalúrgica da UFMG, Belo Horizonte, MG, Brasil.
\end{abstract}




\section{INTRODUÇÃO}

As condições operacionais no processo de sopro do BOF para otimização das reações dependem do correto dimensionamento do bico de lança responsável pela transferência do oxigênio a velocidades supersônicas. Para estrutura de múltiplos jatos, Smith ${ }^{(1)}$, apresenta a Figura 1, que descreve o campo de vazão para um jato simples de uma lança com múltiplos bocais para casos com $5^{\circ}$ e $10^{\circ}$ de inclinação com relação ao centro.

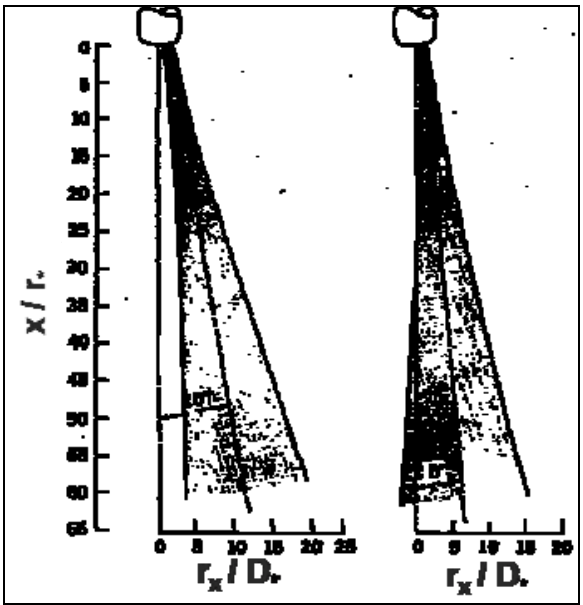

Figura 1 - Comparação entre inclinações de jato(1).

O centro da saída do bocal está a aproximadamente um diâmetro da linha de centro da lança sendo este um típico "layout" de muitas lanças de 03 bocais em operação. Para $10^{\circ}$ ou inclinações maiores, o contorno interno do jato corre paralelo com a linha de centro da lança e os jatos não têm uma interseção. Para o caso de $5^{\circ}$, o contorno interno do jato cruza com a linha de centro da lança próximo a 30 diâmetros abaixo e a borda dos jatos seriam interseccionadas depois de alcançar este ponto. Este cruzamento é conhecido como "coalescência de jatos". Efeito semelhante ocorre em função da pressão no reservatório estagnante, conforme apresentado na Figura 2, pelo diagrama de impacto de jato.

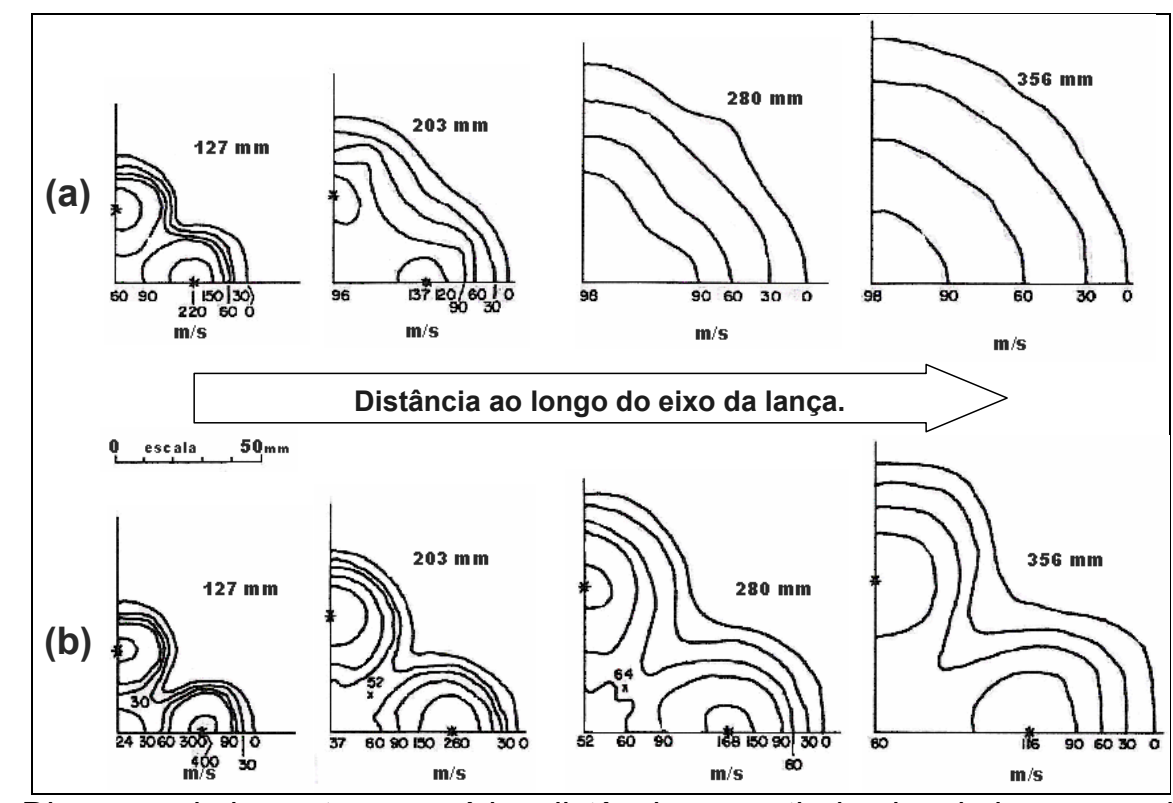

Figura 2 - Diagrama de impacto para várias distâncias a partir do eixo da lança para lança de 04 bocais sendo: (a) $7,24 \times 10^{5} \mathrm{~Pa}$ e (b) $10,69 \times 10^{5} \mathrm{~Pa}^{(2)}$. 
O grau de coalescência aumenta com a queda da pressão estagnante. Para pressões maiores não existe uma completa coalescência e sempre permanece alguma incidência dos quatro jatos originais. Lee et $\mathrm{al}^{(2)}$ explicam o fenômeno da coalescência de jato tomando uma vista no plano de direção $Y-Y$, apresentada na Figura 3.

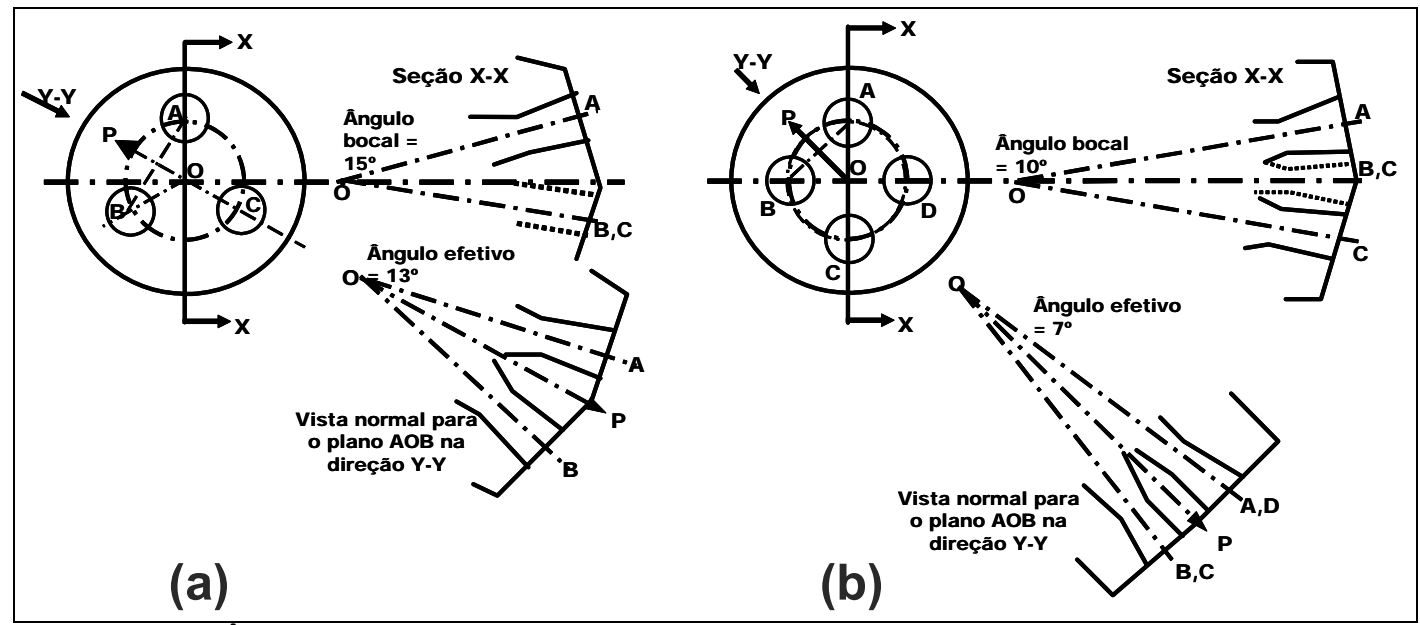

Figura 3 - Ângulo efetivo entre bocais adjacentes para: a) 03 bocais e b) 04 bocais $^{(2)}$.

A Figura 3 mostra que o ângulo entre o eixo de dois bocais é $26^{\circ}$ para uma lança de 03 bocais e $14^{\circ}$ para 04 bocais. Desta forma, neste plano os semi-ângulos efetivos (ângulos de espalhamento) são $13^{\circ}$ e $7^{\circ}$, sendo menores que os respectivos ângulos entre os bocais e o eixo da lança. Um jato interferirá com outro se seus contornos encontrarem algum outro ao longo da linha OP, a bissetriz do ângulo entre os eixos dos bocais. Para lanças de 03 bocais, os contornos de jato divergem um do outro em um ângulo de $+5,5^{\circ}\left(13,0^{\circ}-7,5^{\circ}\right)$. Com lanças de 04 bocais, este ângulo de divergência é de $-0,5^{\circ}\left(7,0^{\circ}-7,5^{\circ}\right)$, significando o sinal negativo que o efeito de contorno de jato deve ser em algum lugar ao longo da linha OP.

Igualmente importante é o efeito da sucção entre os jatos adjacentes que suga o ar secundário para os limites de volume avaliados no centro da lança. Para este caso, coalescência é por definição causada pela fusão dos jatos, em estágios prematuros, determinando os graus de coalescência mais severos, sendo a sucção apenas um efeito ${ }^{(3-4)}$. O presente trabalho tem por objetivo realizar uma análise da relação entre ângulos de bicos multibocais dos convertedores atuais e propor opções para o futuro.

\section{MATERIAIS E MÉTODOS}

Para o estudo foram comparados bicos multibocais de convertedores com capacidade de produção entre $30 \mathrm{t}$ a $350 \mathrm{t}$ toneladas vazadas por corrida em operação ao redor do mundo.

Nos bicos multibocais foram comparadas as influências do: ângulo dos bocais com a vertical, ângulo entre bocais em relação a horizontal, ângulo do cone divergente dos bocais, ângulo com relação a vertical de bocais adjacentes e PCD (Primary Circle Diameter), conforme representado na Figura 4. 


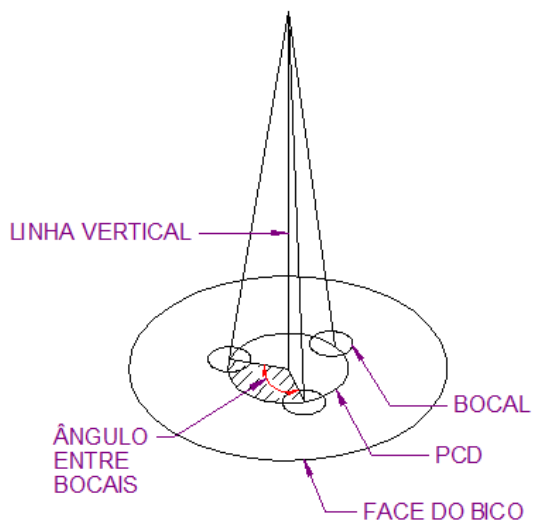

(a)

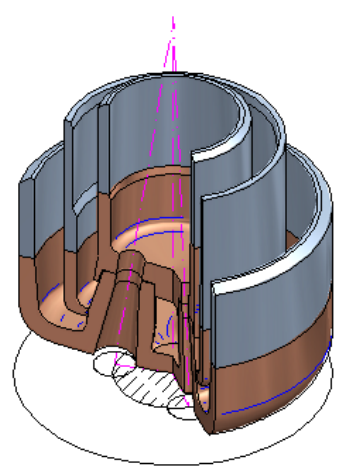

(d)

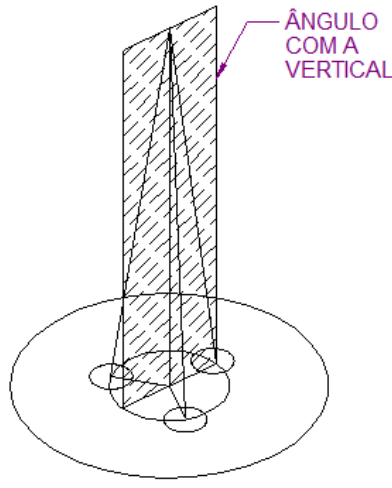

(b)

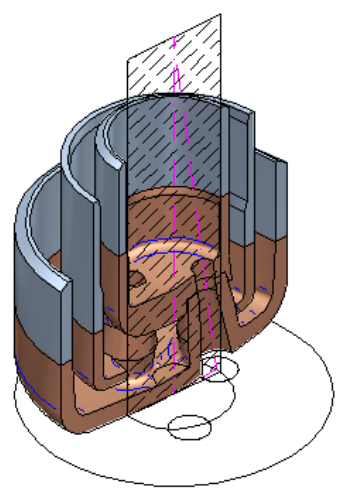

(e)

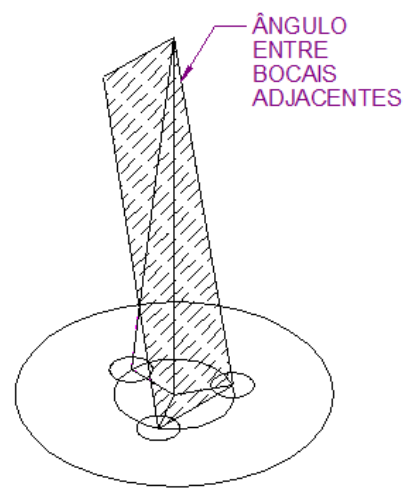

(c)

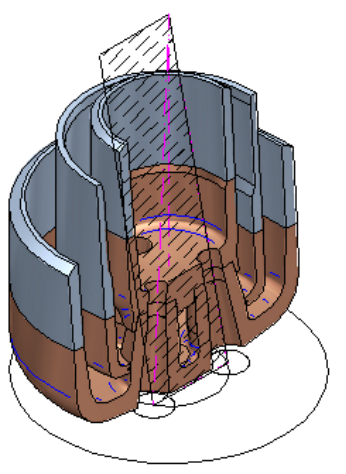

(f)

Figura 4 - Ângulos existentes em bicos multibocais: a) Apresentação da Linha vertical; Ângulo entre Bocais; Face do bico; PCD: Diâmetro do ciclo primário; Bocal, b) Apresentação do plano do ângulo com a vertical; c) Apresentação do plano do ângulo entre bocais adjacentes, d) Representação do corte ângulo entre Furos, e) Representação do corte ângulo com a vertical e f) Representação do corte ângulo entre bocais adjacentes.

\section{RESULTADOS E DISCUSSÃO}

O número de bocais determina, dentro de um diâmetro primitivo (PCD), um ângulo entre bocais com relação à horizontal. Esse ângulo tem forte influência no ângulo entre bocais adjacentes e o ângulo com a vertical. A Figura 5 apresenta a relação entre número de bocais e ângulos de bicos operando em convertedores ao redor do mundo e também uma extrapolação de número de bocais e ângulos.

Na Figura 5 (a), o eixo das abscissas mostra o número de bocais e no eixo das ordenadas os ângulos entre bocais adjacentes e ângulos dos bocais com a vertical. É possível notar que para um mesmo número de bocais existem diferentes ângulos com vertical, mas de forma geral com o acréscimo do número de bocais é acrescido também o ângulo com a vertical. Comportamento inverso ocorre com ângulo entre bocais adjacentes que possuem, em comparação com ângulo com a vertical, valores superiores podendo contribuir para o efeito de coalescência de jato. Os bicos com 06 bocais constituem um caso especial e peculiar, pois devido à formação em relação ao centro de bico e dois bocais adjacentes, formam-se triângulos equiláteros conferindo ângulos iguais entre a vertical e bocais adjacentes. Após os bicos de 06 bocais, o ângulo com vertical passa a ser superior ao ângulo adjacente, eliminando a possibilidade de coalescência devido à geometria. Em função da variedade de 
projetos existentes, a correlação entre ângulo com a vertical e ângulo entre bocais adjacentes não foi significativo.

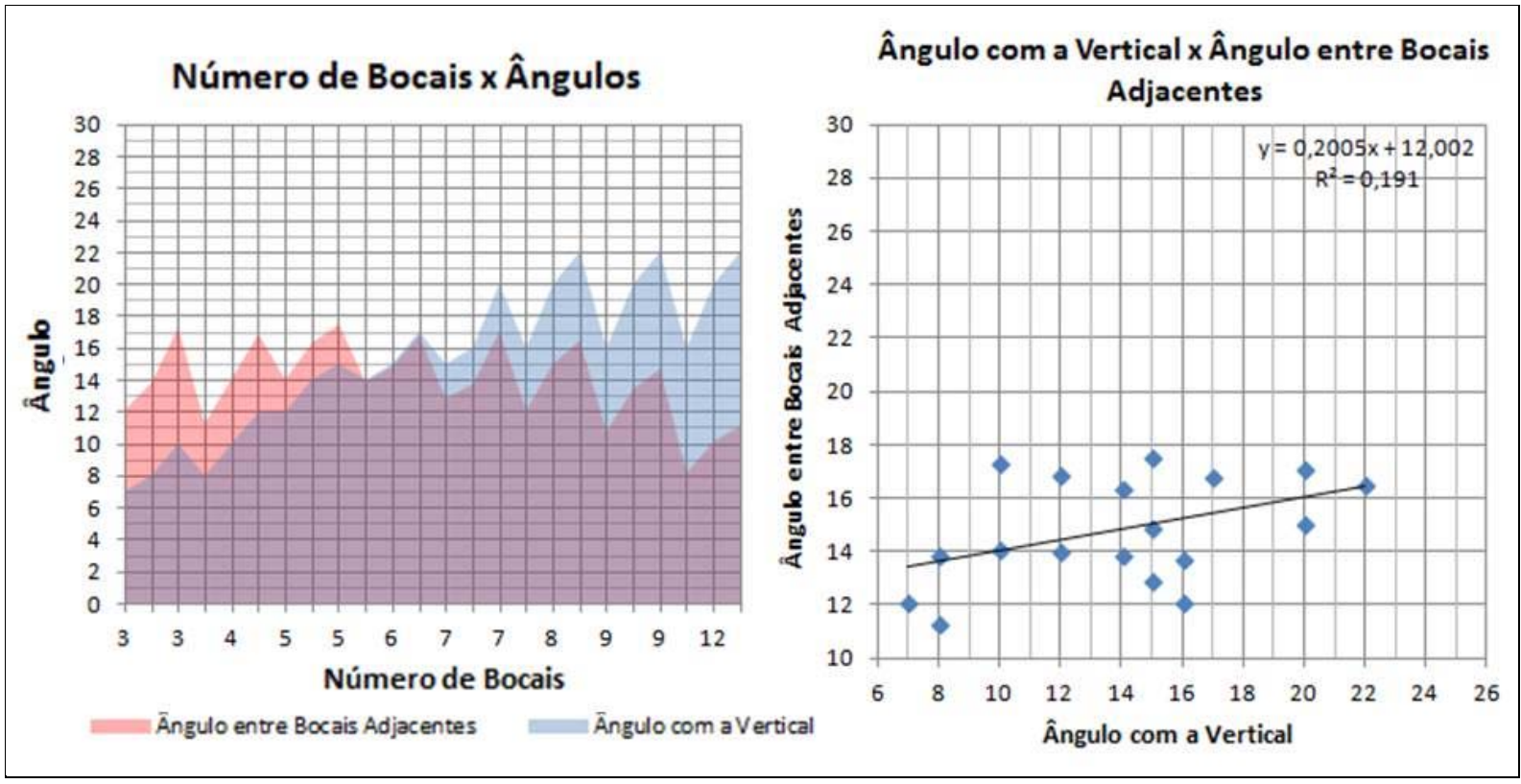

\section{a)}

b)

Figura 5 - Bicos de lança em operação pelo mundo e novas geometrias: a) Relação entre número de bocais e ângulos e b) correlação entre ângulo com a vertical e ângulo entre bocais adjacentes.

Na Figura 6 foram selecionadas configurações de bico de lança típicas nas usinas e feitas extrapolações.

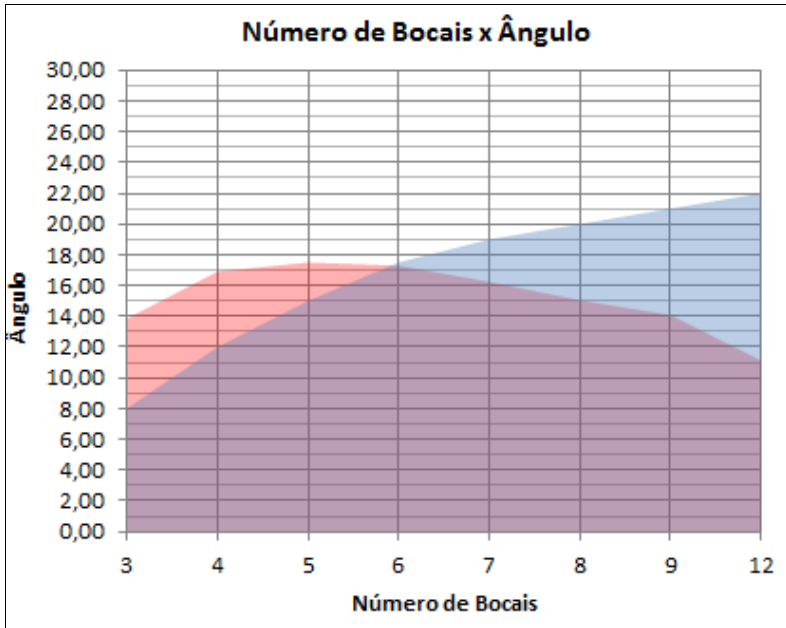

Ângulo entre Bocais Adjacentes ângulo com a Vertical

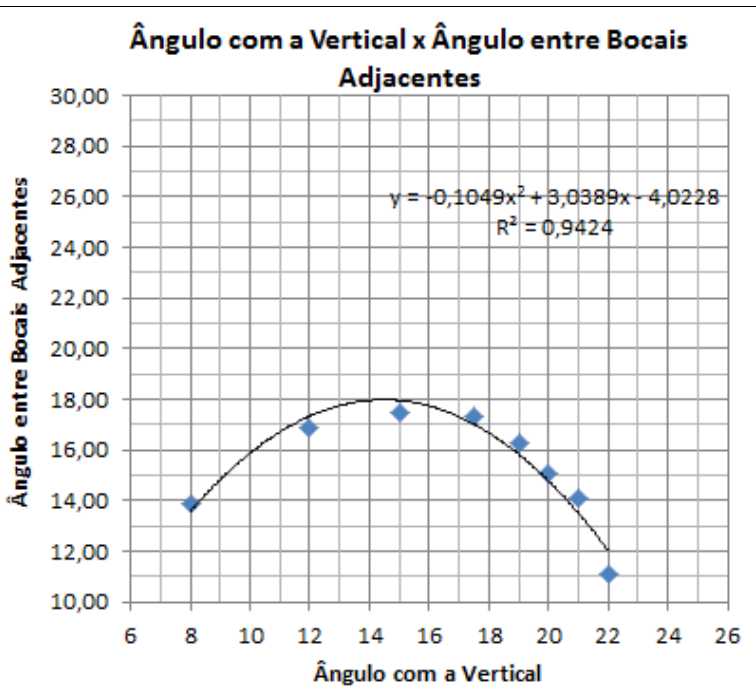

b)

Figura 6 - Bicos típicos e novas geometrias: a) Relação entre número de bocais e ângulos e b) correlação entre ângulo com a vertical e ângulo entre bocais adjacentes.

É interessante notar novamente a peculiaridade geométrica do bico de 06 bocais, tendo mesma inclinação vertical com ângulo entre bocais adjacentes. Bicos abaixo de 06 bocais têm ângulo com vertical inferior ao ângulo entre bocais adjacentes e potencialmente a possibilidade de ocorrer coalescência de jato. Bicos acima de 06 bocais têm comportamento inverso, eliminando a possibilidade de coalescência de 
jato muito embora sejam casos hipotéticos, pois de fato não existem essas configurações em funcionamento nos convertedores.

Com a seleção de configurações típicas por número de bocais, é possível notar o comportamento parabólico com boa correlação entre o ângulo dos bocais com a vertical e ângulo entre bocais adjacentes. Os valores foram extrapolados até o valor de $22^{\circ}$, enquanto que a prática atual dos convertedores está no ângulo de $17^{\circ}$, considerando $0,5^{\circ}$ de variação.

A Figura 7 apresenta o comportamento fixando o ângulo com vertical dos bocais em $17^{\circ}$ graus.

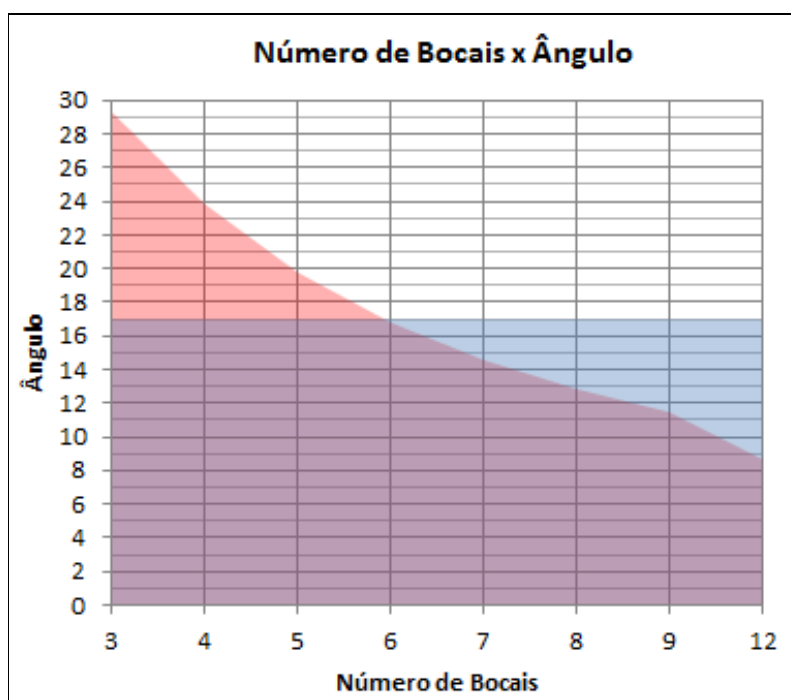

Ângulo entre Bocais Adjacentes Ângulo com a Vertical

a)

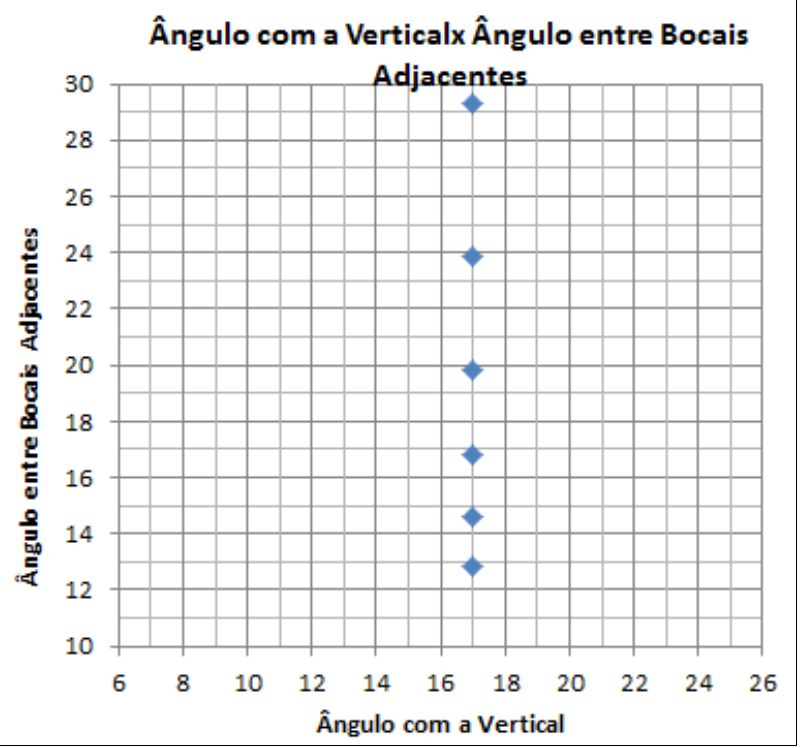

b)

Figura 7 - Bicos $17^{\circ}$ graus com a vertical: a) Relação entre número de bocais e ângulos e b) correlação entre ângulo com a vertical e ângulo entre bocais adjacentes.

Na figura 7 fixando o ângulo com a vertical em $17^{\circ}$ e variando o número de bocais, o comportamento do ângulo adjacente entre bocais permanece o mesmo, mas tornando a possibilidade de coalescência de jato maior com o menor número de bocais.

A Figura 8 apresenta a influência do Círculo de Diâmetro Primário (PCD) para a condição de bico com 06 bocais e ângulo de $17^{\circ} \mathrm{com}$ a vertical.

Na Figura 8 é possível notar que o PCD não exerce influência sobre o ângulo com a vertical e o ângulo adjacente entre bocais, mas em função do ângulo divergente da saída dos bocais pode influenciar na coalescência de jato, pois até o momento ainda não foi verificado o efeito do ângulo da saída divergente dos bocais. Também pode ser notada na Figura 8 a peculiaridade do bico 06 bocais, que apresenta o mesmo ângulo entre a vertical e ângulo entre bocais adjacentes. 


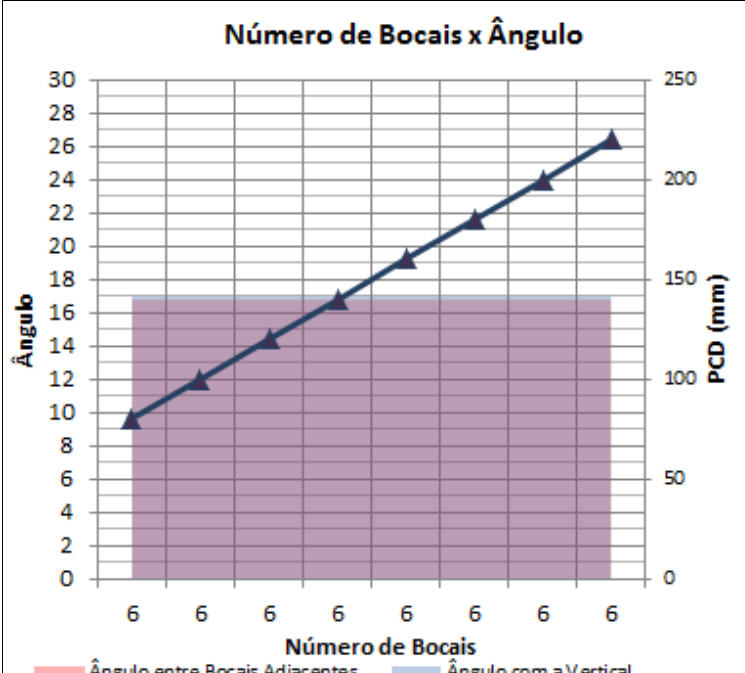

Ângulo entre Bocais Adjacentes Ângulo com a Vertical —PCD (Diâmetro Furos Opostos)

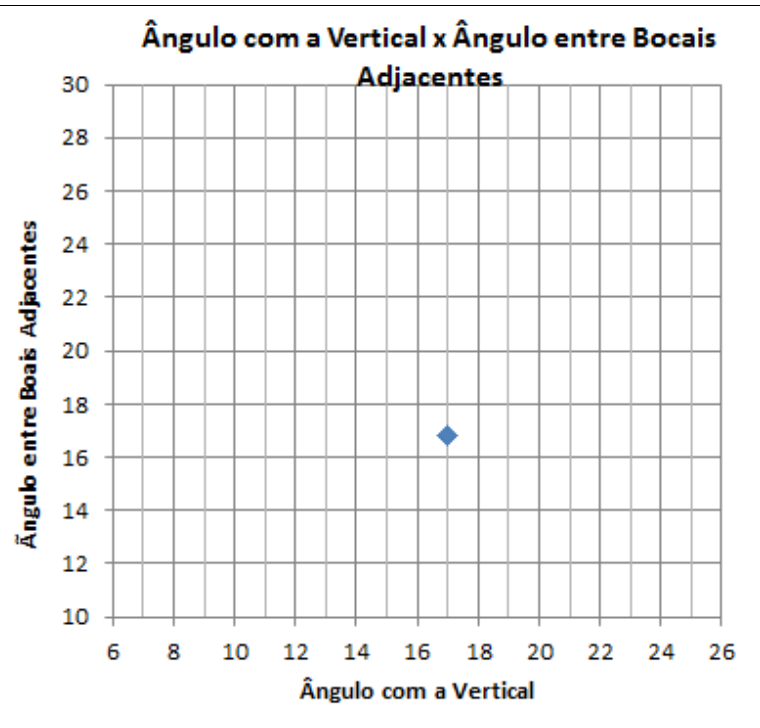

a)

b)

Figura 8 - Bicos 6 bocais $17^{\circ}$ graus com a vertical: a) Relação entre número de bocais, PCD e ângulos e b) correlação entre ângulo com a vertical e ângulo entre bocais adjacentes.

A Figura 9 apresenta a disposição dos ângulos entre bocais adjacentes, ângulos entre furos na face dos bicos, ângulos com a vertical e o círculo de diâmetro primário (PCsD) para a condição de bico 06 bocais e ângulo de $17,5^{\circ} \mathrm{com}$ a vertical.

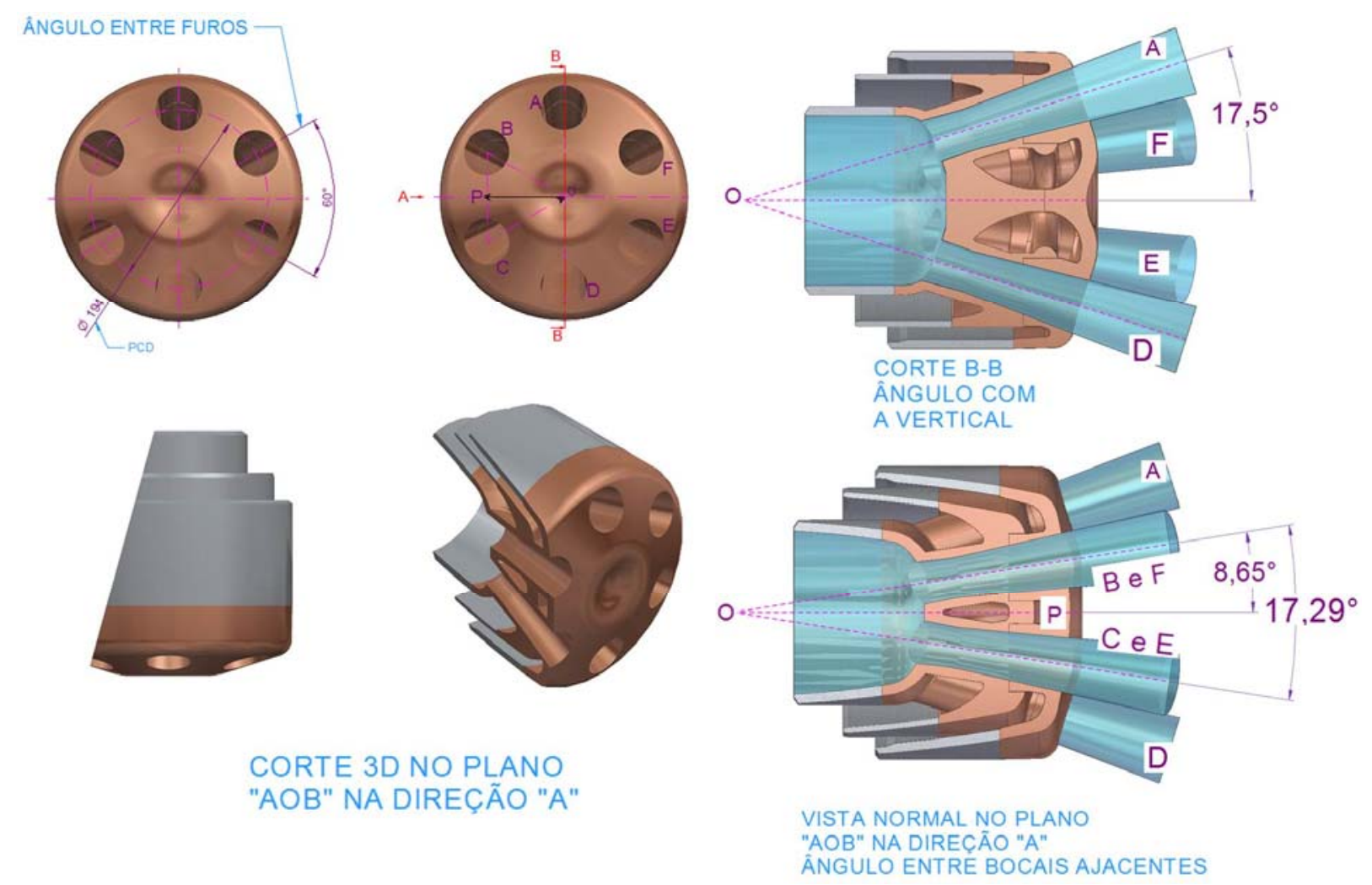

Figura 9 - Representação bico com 6 bocais $17,5^{\circ}$ graus com a vertical 
Pode ser notado que neste plano os semiângulos efetivos (ângulos de espalhamento) são $17,5^{\circ}$, sendo maiores que os respectivos ângulos entre os bocais e o eixo da lança que são $8,65^{\circ}$. Sendo assim evitado o efeito da coalescência, como apresenta a Figura 10.

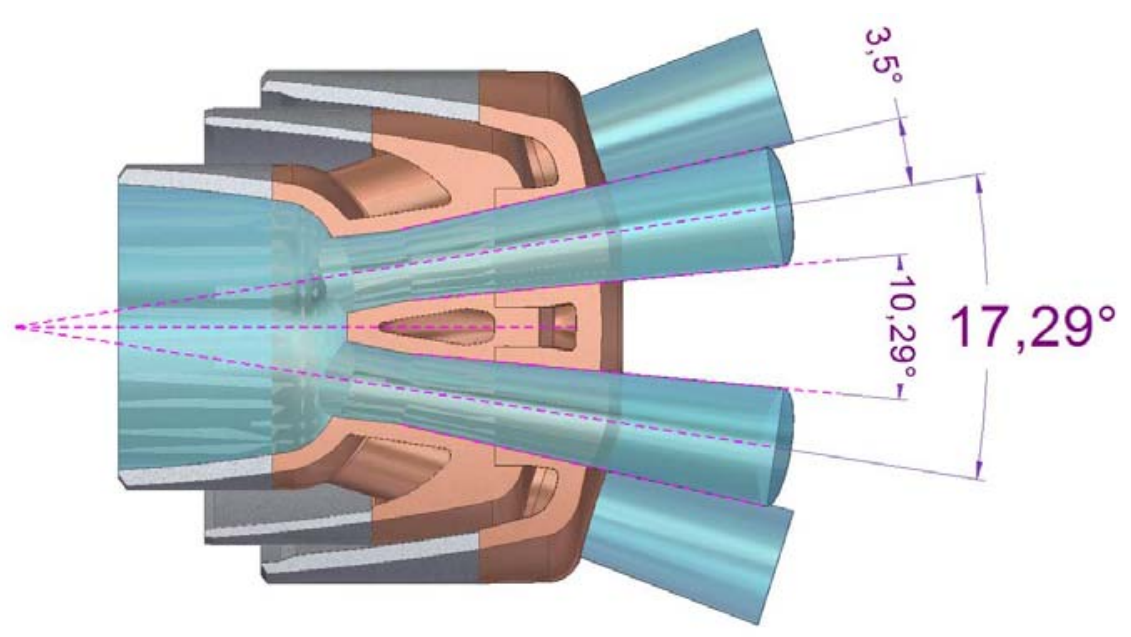

Figura 10 - Verificação da coalescência de jato para bico com 6 bocais $17,5^{\circ}$ graus com a vertical

Com intuito de verificar o comportamento fora dessa condição específica, foi gerada a Figura 11, que apresenta a influência do Círculo de Diâmetro Primário (PCD) para a condição de bico 03 bocais e ângulo de $8^{\circ} \mathrm{com}$ a vertical.

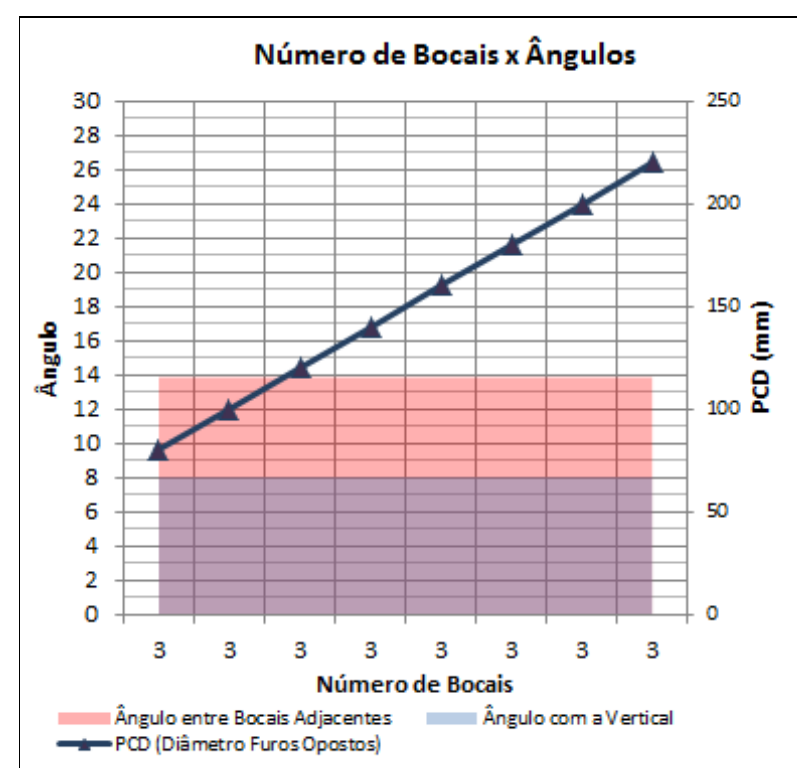

a)

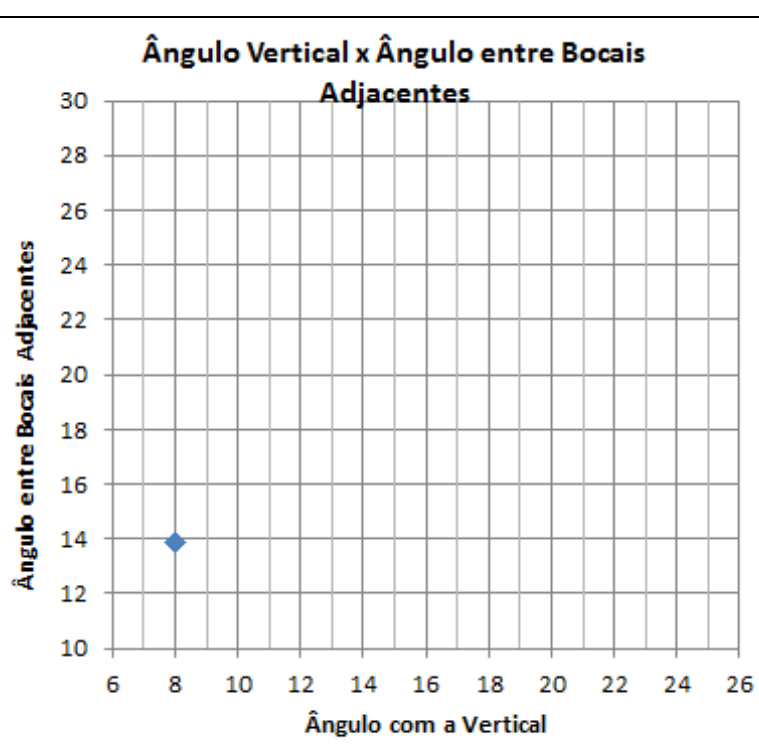

b)

Figura 11 - Bicos 3 bocais $8^{\circ}$ graus com a vertical: a) Relação entre número de bocais, PCD e ângulos e b) correlação entre ângulo com a vertical e ângulo entre bocais adjacentes.

Na Figura 11 fica evidente que, independente da dimensão do PCD, o ângulo entre bocais adjacentes permanece o mesmo e o valor é superior ao ângulo dos bocais em relação a vertical, podendo ocorrer o efeito da coalescência de jato. 

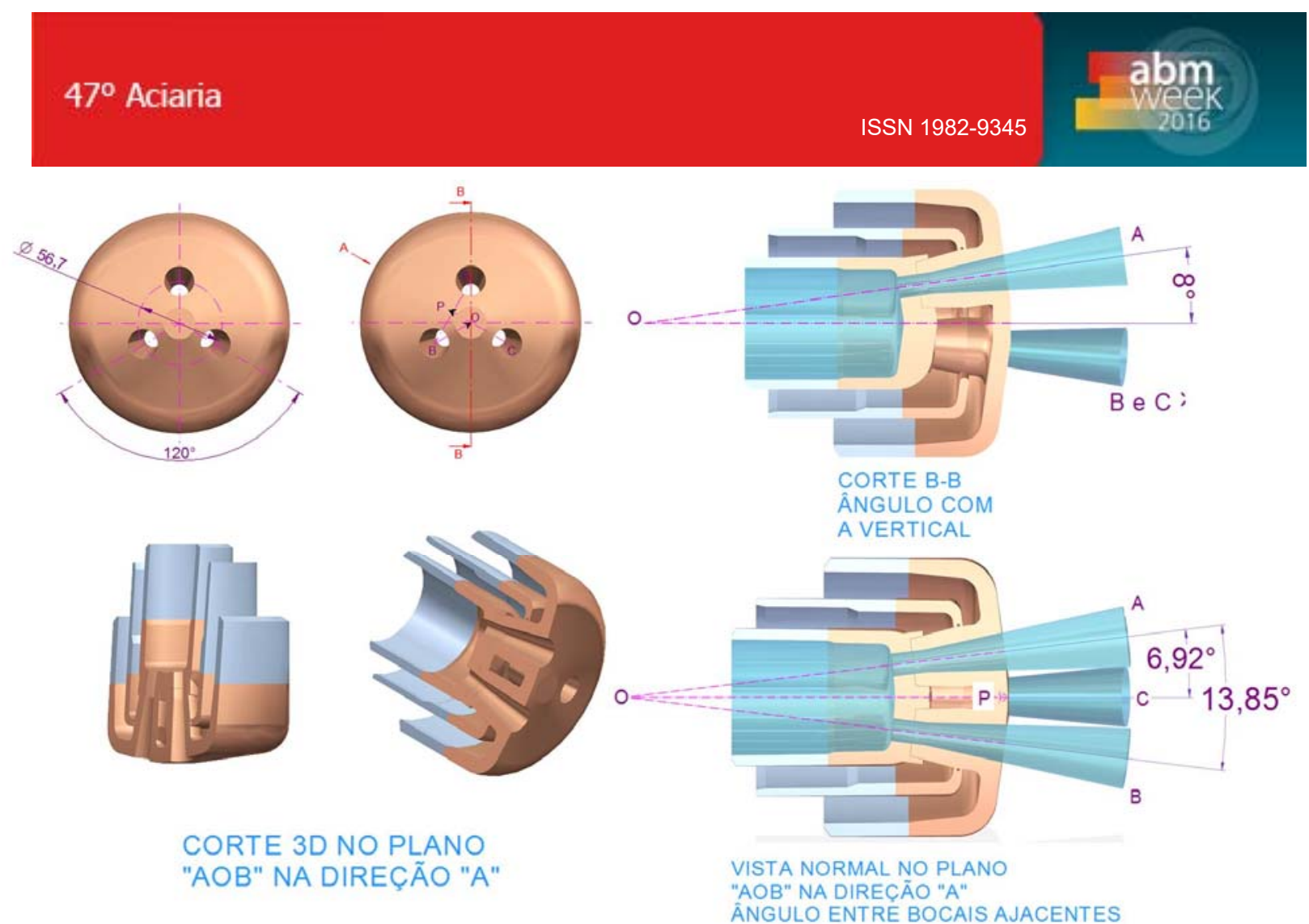

Figura 12 - Representação bico com 3 bocais $8^{\circ}$ graus com a vertical.

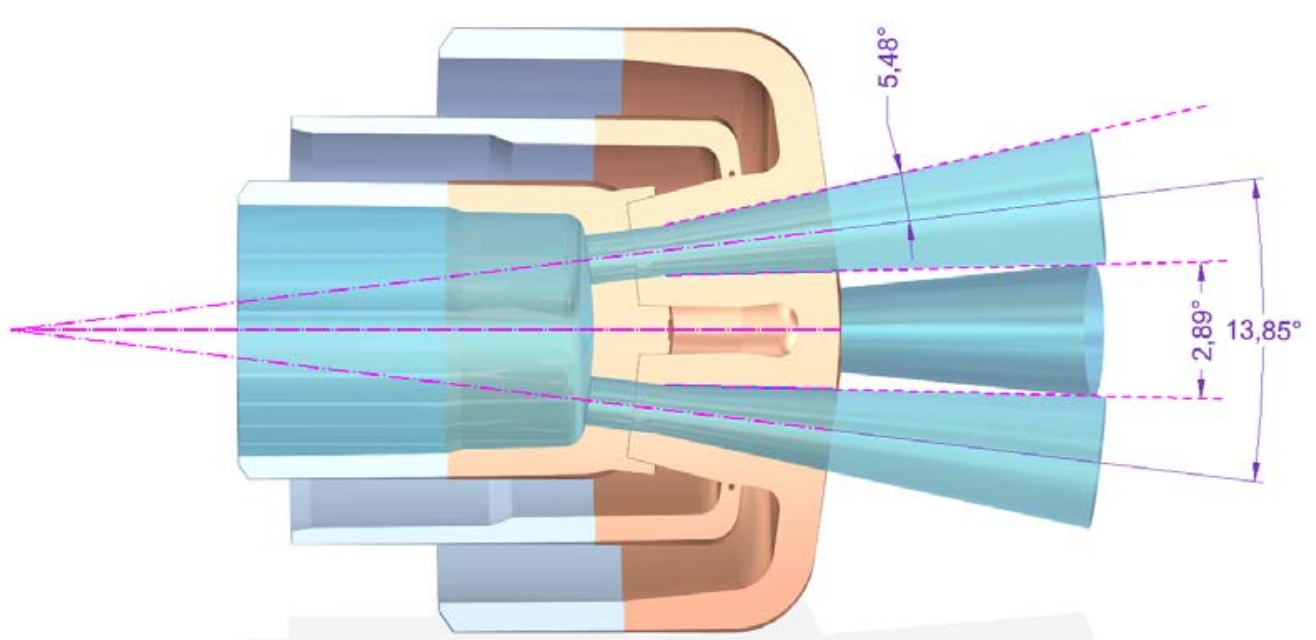

Figura 13 - Verificação da coalescência de jato para bico com 3 bocais $8^{\circ}$ graus com a vertical.

A Figura 14 corresponde a um bico industrial com ângulo com a vertical de $10^{\circ} \mathrm{e}$ o ângulo da saída divergente do bocal de $22^{\circ}$. Pode ser notado que o ângulo entre bocais adjacentes foi superior ao ângulo com a vertical, ocorrendo então o efeito da coalescência de jato, conforme ilustrado na figura 15. 

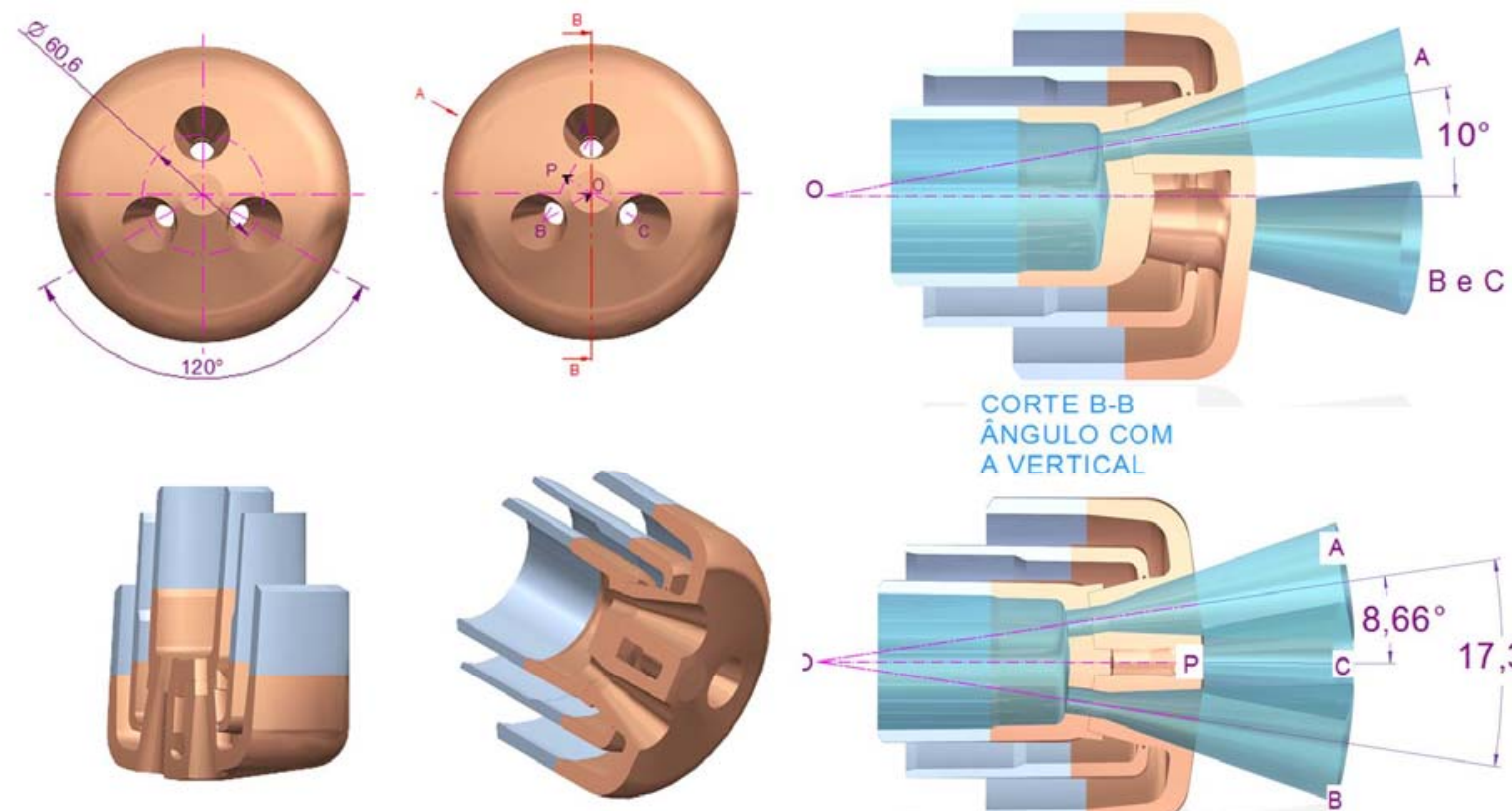

ANGULO COM

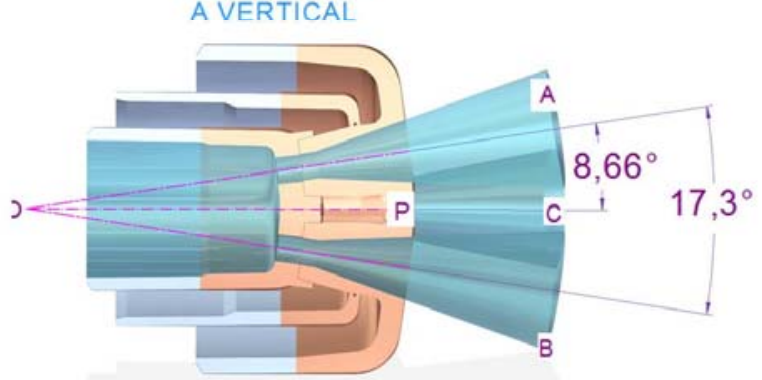

CORTE 3D NO PLANO

"AOB" NA DIREÇÃO "A"

VISTA NORMAL NO PLANO

"AOB" NA DIRECẼ̃O "A"

ÂNGULO ENTRE BOCAIS AJACENTES

Figura 14 - Representação bico com 3 bocais $10^{\circ}$ graus com a vertical.

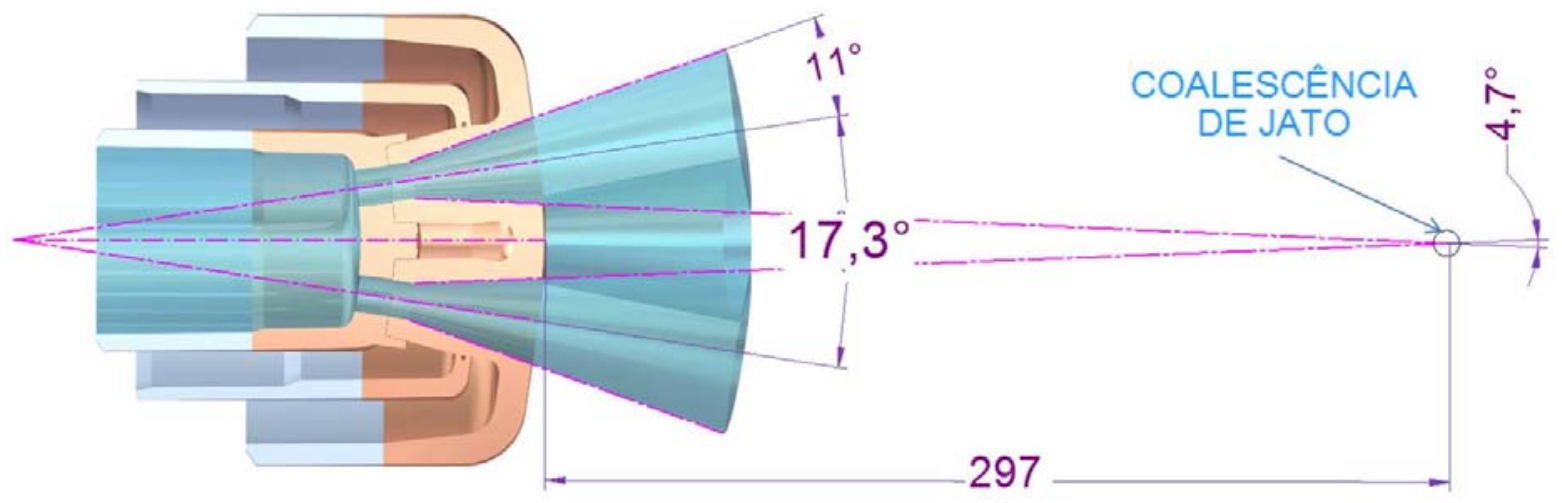

Figura 15 - Verificação da coalescência de jato para bico com 3 bocais $10^{\circ}$ graus com a vertical.

Para verificar a influência do ângulo da saída divergente sobre o efeito da coalescência, foram coletados esses valores de bocais em operação. O resultado é apresentado na Figura 16. 


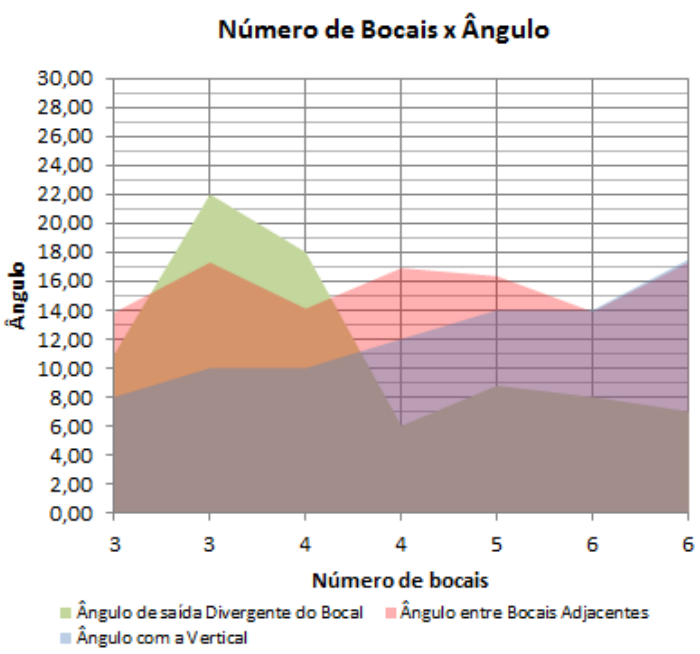

a)

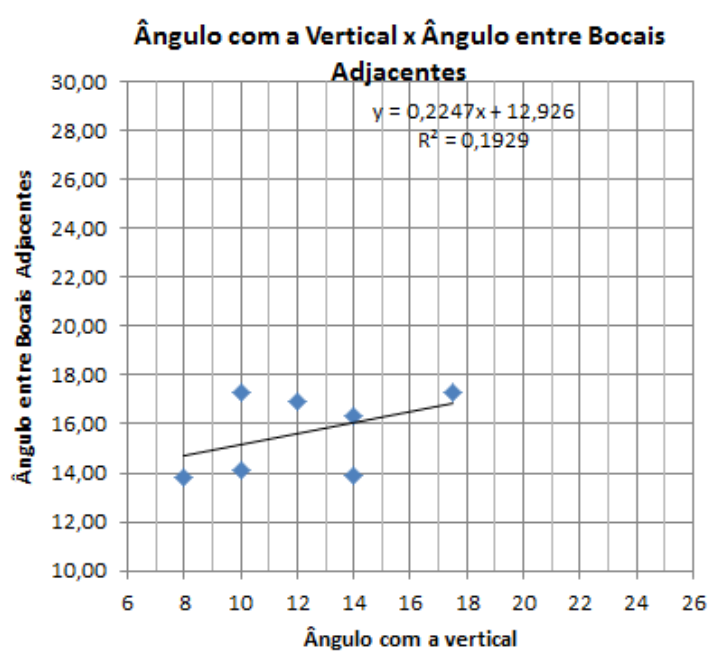

b)

Figura 16 - Bicos de lança em operação pelo mundo: a) Relação entre número de bocais e ângulos incluindo ângulo da saída divergente do bocal e b) correlação entre ângulo com a vertical e ângulo entre bocais adjacentes.

Na Figura 16 observa-se que bicos entre 3 e 4 bocais apresentam ângulos da saída divergentes entre $14^{\circ}$ e $22^{\circ}$ e podem apresentar coalescência de jato. Bicos com mais de 5 bocais apresentam o valor máximo de $14^{\circ}$ de ângulo da saída divergente. A combinação dos ângulos de bocais adjacentes com o ângulo da saída divergente é um dos determinantes para coalescência de jato, conforme apresentado na Figura 17.

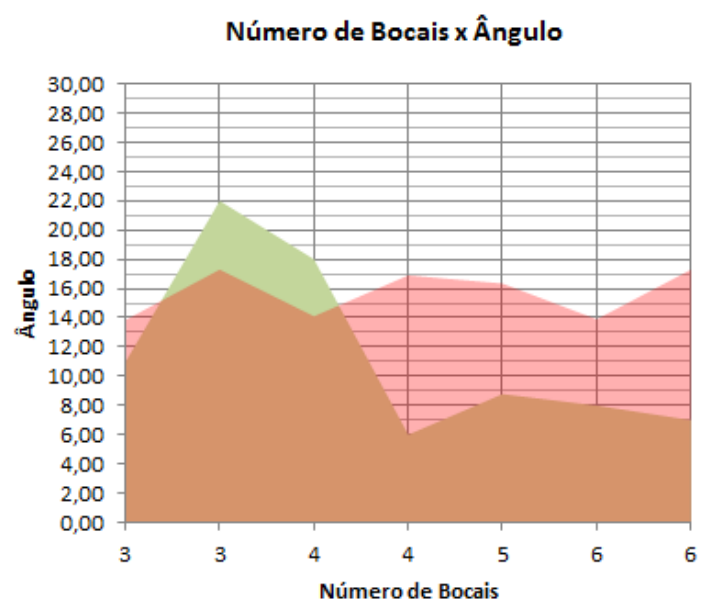

\#Ângulo de saida Divergente do Bocal $=$ Ângulo entre Bocais Adjacentes

a)

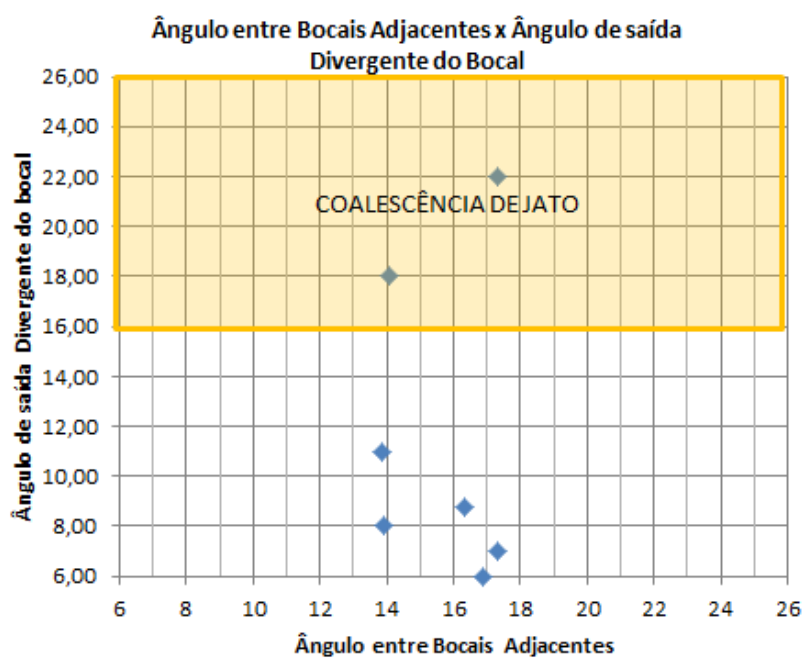

b)

Figura 17 - Bicos de lança em operação pelo mundo: a) Relação entre número de bocais e ângulos entre bocais adjacentes e ângulo da saída divergente do bocal e b) correlação entre ângulo entre bocais adjacentes e o ângulo da saída divergente do bocal.

A Figura 17 mostra não existir uma correlação entre os ângulos, mas permite demonstrar que bocais, quando os ângulos da saída divergente são superiores ao ângulo entre bocais adjacentes, irão promover jatos que sofrerão os efeitos da coalescência. 
A Figura 18 apresenta um bico com 4 bocais e ângulo com a vertical de $12^{\circ}$. Conforme discutido anteriormente, pode ser notado na imagem que o ângulo entre bocais adjacentes é inferior ao ângulo com a vertical, não configurando o efeito da coalescência de jato, conforme visto na figura 19.
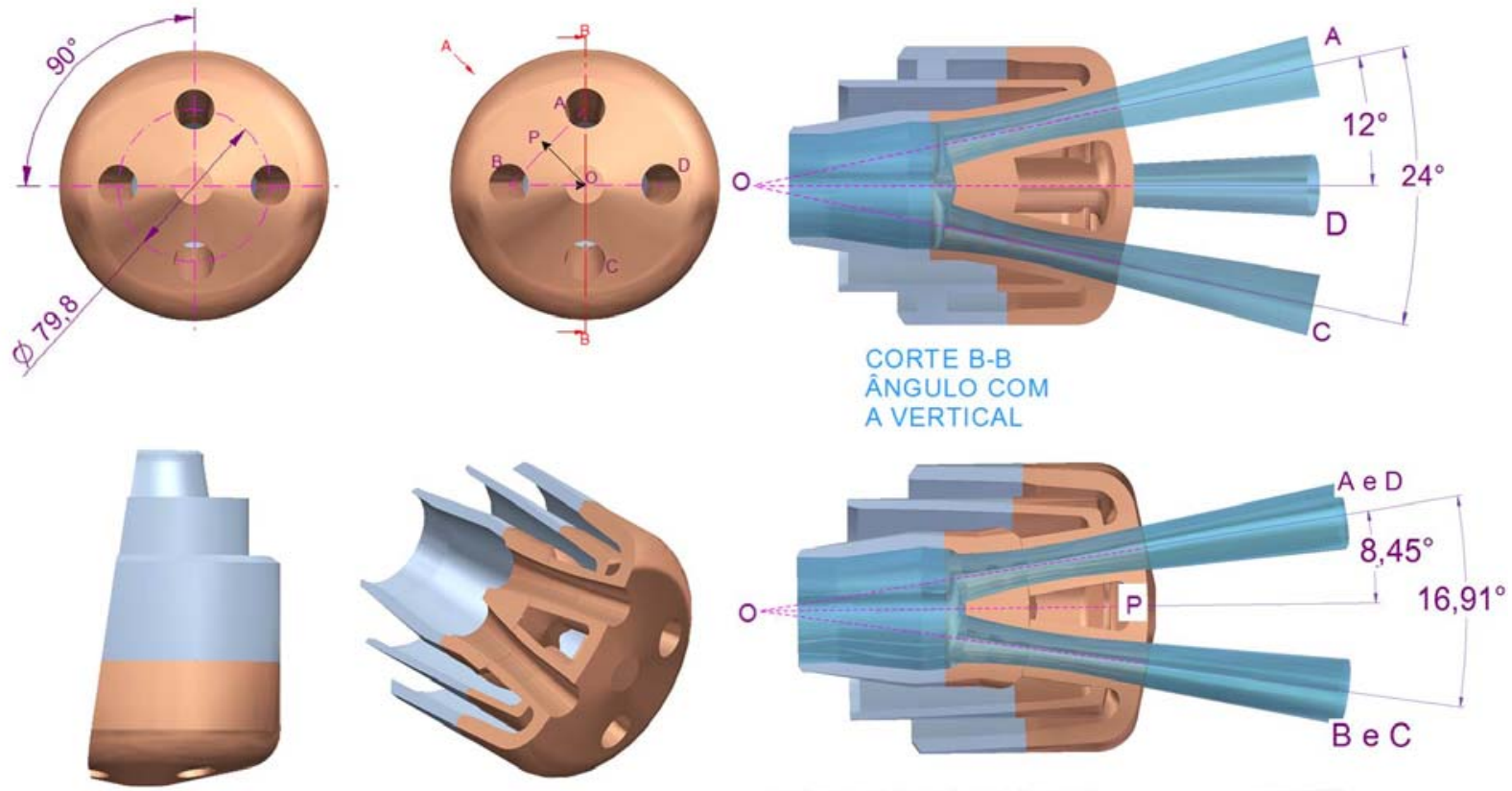

CORTE 3D NO PLANO

"AOB" NA DIREÇÃO "A"

VISTA NORMAL NO PLANO

"AOB" NA DIRECCÃO "A"

ÂNGULO ENTRE BOCAIS AJACENTES

Figura 18 - Representação bico com 4 bocais $12^{\circ}$ graus com a vertical.

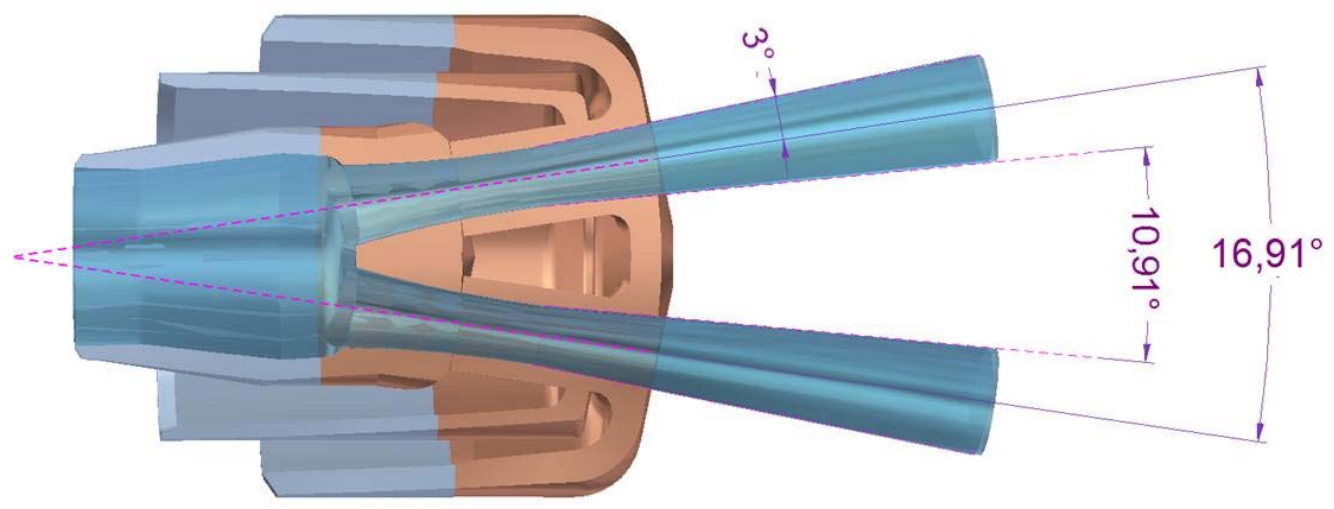

Figura 19 - Verificação da coalescência de jato para bico com 4 bocais $12^{\circ}$ graus com a vertical

A Figura 20 apresenta uma configuração semelhante à do bico apresentado na Figura 18, porém com o ângulo com a vertical de $10^{\circ}$, praticado na indústria, e a saída divergente do bocal de $18^{\circ}$. A partir disso, pode ser notado que o ângulo entre bocais adjacentes é superior ao ângulo com a vertical, configurando então o efeito da coalescência de jato, conforme apresenta a Figura 21. 

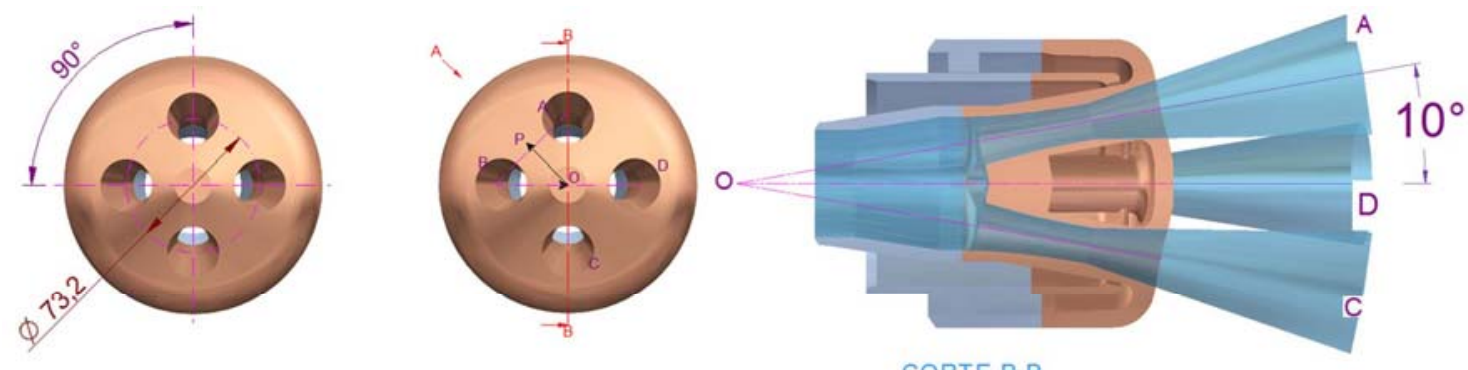

CORTE B-B

ÂNGULO COM
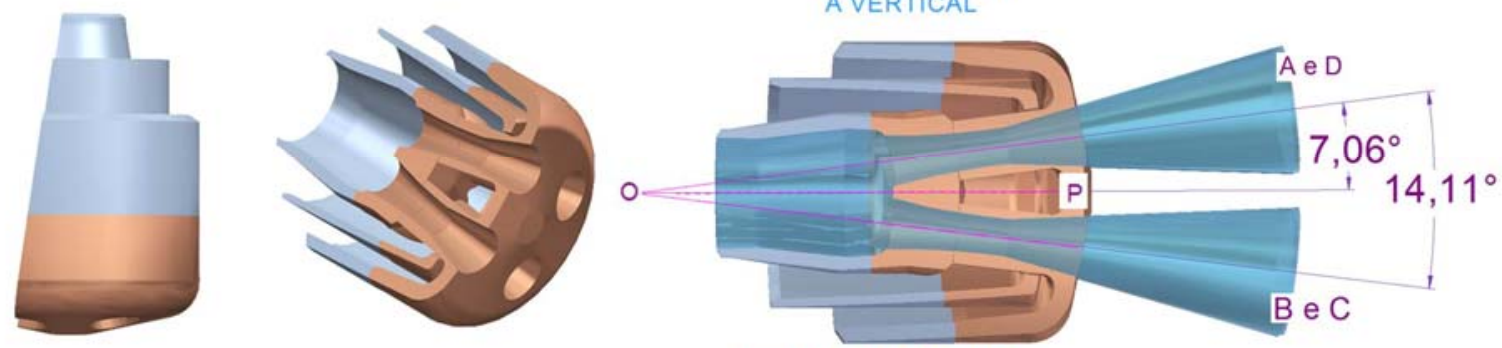

CORTE 3D NO PLANO "AOB" NA DIREÇÃO "A"

Figura 20 - Representação bico com 4 bocais $10^{\circ}$ graus com a vertical.

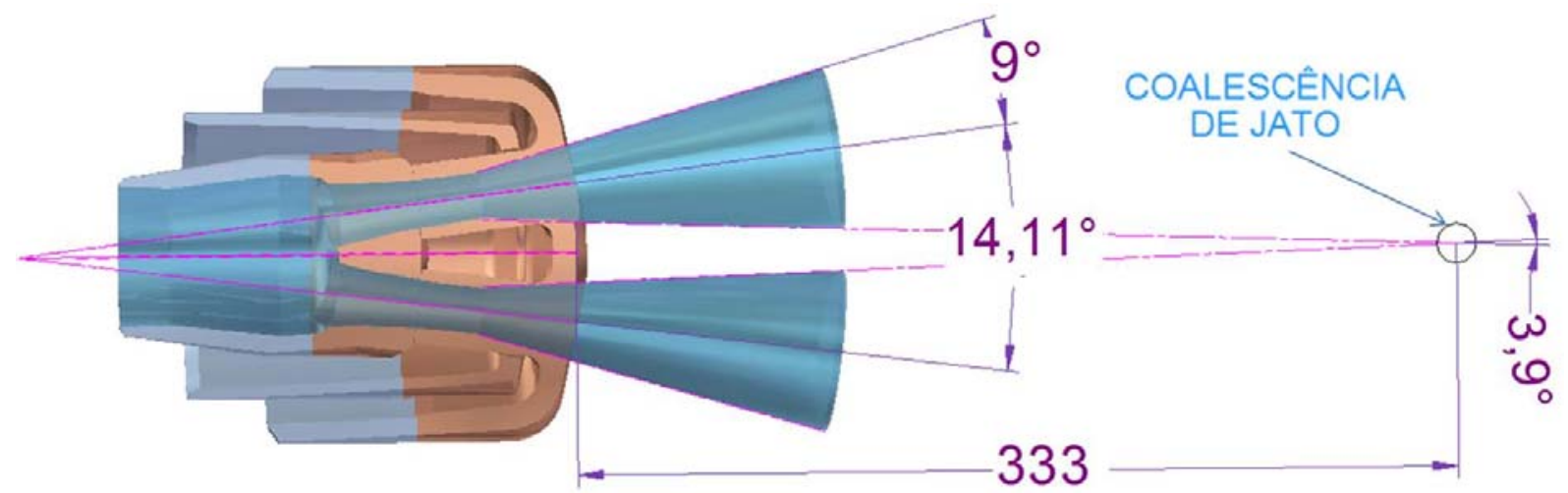

Figura 21 - Verificação da coalescência de jato para bico com 4 bocais $10^{\circ}$ graus com a vertical

Para não ocorrer a coalescência de jato na Figura 21, o ângulo da saída divergente deveria ser no máximo de $16^{\circ}$ para que os jatos saíssem em condição de paralelismo uns em relação aos outros.

As mesmas condições são analisadas para um bico com 5 bocais e ângulo de $14^{\circ}$ com a vertical, conforme apresentado na Figura 22. O ângulo entre bocais adjacentes é inferior ao ângulo com a vertical, não se configurando o efeito da coalescência de jato, conforme apresenta a Figura 23. 

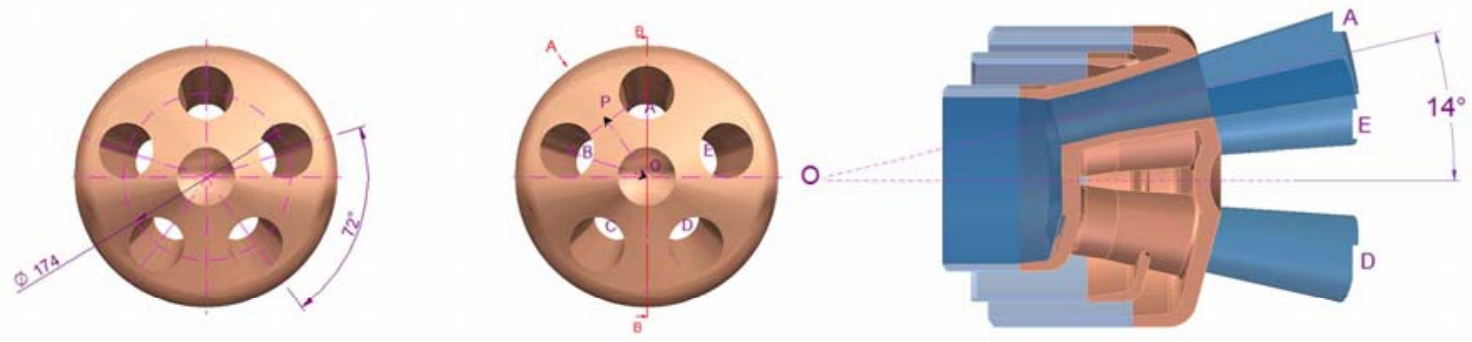

CORTE B-B

ÂNGULO COM

A VERTICAL
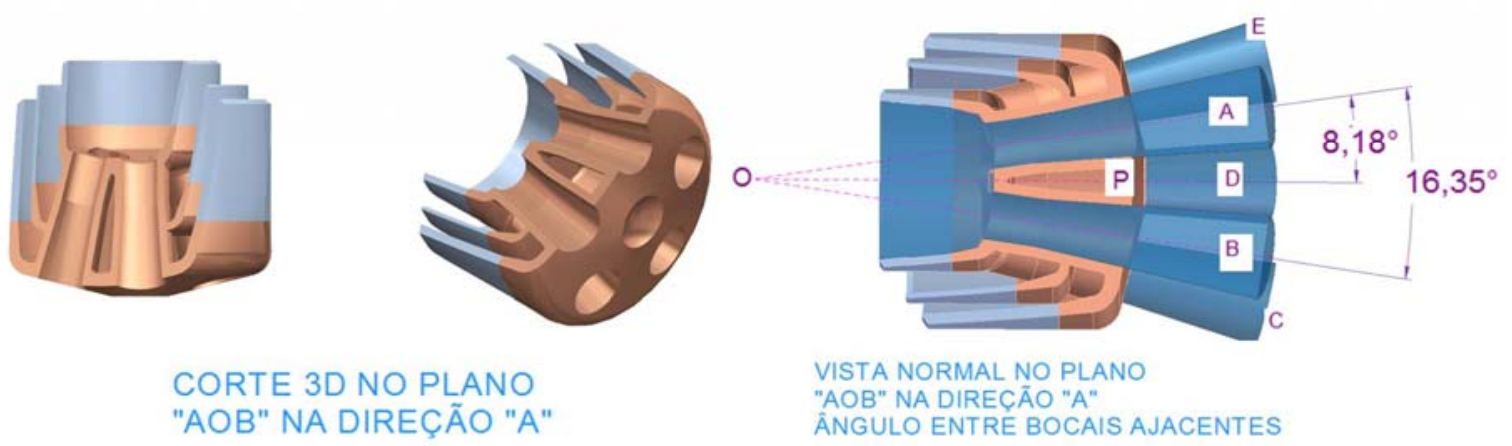

CORTE 3D NO PLANO "AOB" NA DIREÇÃO "A"

Figura 22 - Representação bico com 5 bocais $14^{\circ}$ graus com a vertical.

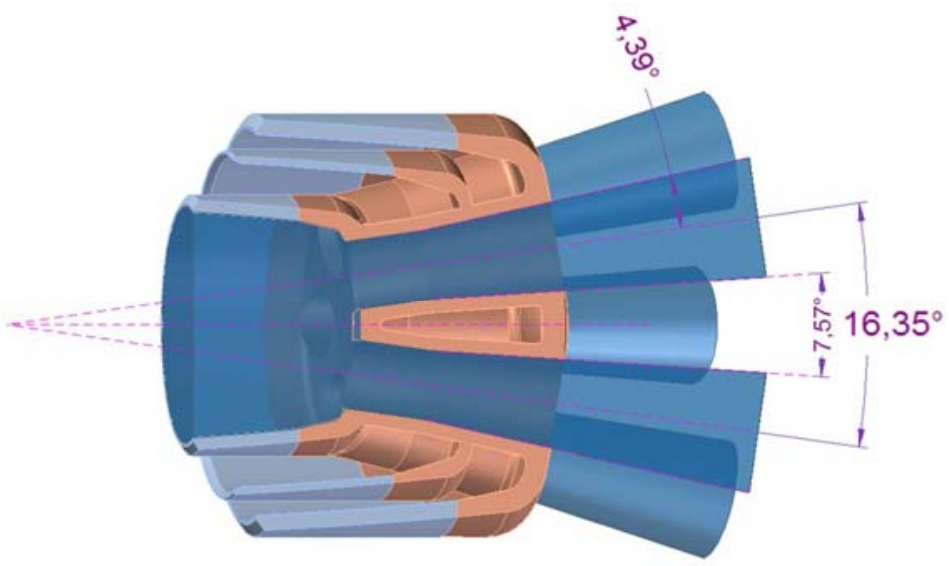

Figura 23 - Verificação da coalescência de jato para bico com 5 bocais $14^{\circ}$ graus com a vertical

Nesse ponto cabe ressaltar que a geometria do bocal sofre influência de outros parâmetros, notadamente a pressão do reservatório estagnante, sendo quanto maior for seu valor, maior a tendência de reduzir o ângulo da saída divergente. Existe a influência do ambiente do forno a elevadas temperaturas assim com as reações de combustão e pós-combustão que ocorrem durante o sopro ${ }^{(5-6)}$,assim como também a velocidade de jato, sendo esses assuntos não aprofundados nesse estudo. Da mesma forma que o ângulo da saída divergente do bocal é fortemente influenciado pela vazão desejada por cada aciaria assim como a necessidade de promover a necessária refrigeração do bico. Estes tópicos não foram objeto desse estudo, centrado apenas nas características trigonométricas dos bocais. 


\section{CONCLUSÃO}

As principais conclusões do trabalho são:

1. PCD não exerce influência sobre o ângulo com a vertical e o ângulo adjacente entre bocais, mas em função do ângulo divergente da saída dos bocais pode influenciar na coalescência de jato;

2. A combinação dos ângulos de bocais adjacentes com o ângulo da saída divergente e ângulo com a vertical são determinantes para coalescência de jato;

3. Quanto maior for o ângulo da saída do divergente do bocal, maior a probabilidade de ocorrer coalescência de jato;

4. Quando ângulo entre dois bocais adjacentes for superior ao ângulo com vertical, ocorrerá a coalescência de jato;

5. Os bicos estudados com até 04 bocais, quando combinado com pequeno ângulo com a vertical e maiores ângulos de saída divergente do bocal são mais propícios a ocorrerem o efeito de coalescência;

6. Os bicos estudados com 05 bocais são menos propícios ao efeito de coalescência, pois o ângulo com a vertical esta estabelecido entre $14^{\circ}$ e $17,5^{\circ}$ sendo superiores aos ângulos adjacentes dos projetos, sendo assim eliminando o efeito de coalescência;

7. Embora ainda não existam bicos acima de 06 bocais; foram extrapolados dados no presente mostrando serem menos propícios ao efeito da coalescência;

8. Os métodos gráficos apresentados são mostram-se ferramentas importantes para um bom projeto de bico de convertedor BOF.

\section{Agradecimentos}

Os autores agradecem a Lumar Metals e a UFMG.

\section{REFERÊNCIAS}

1. SMITH, G. C., Multiple Jet Oxygen Lances -Theoretical Analysis and Correlation With Pratice. Journal of Metals. P.846 - 851, jul.1966.

2. LEE, C. K., NEISON, J. H., GILCHRIST, A. Correlation of the Decay Characteristics of Jets from Multi-nozzle Oxygen Lances with the Performance of the Charge in Steel Converters, Iron and Steel Internacional, p.175-184, jun.1977.

3. MAIA, B. T., Modelamento Físico e Matemático do Escoamento de Fluidos nos processos BOF e EOF. Belo Horizonte: Escola de Engenharia da UFMG, 2013. 238p. (Tese, Doutorado em Engenharia Metalúrgica).

4. MAIA, B.T. e outros: Lança de Oxigênio. Curso de Aciaria a Oxigênio, Associação Brasileira de Metalurgia e Materiais - ABM, Rio de Janeiro - RJ, 2012.

5. MAIA, B. T., BARROS, J. E. M., NASCIMENTO, L. M., GUERRA, M. S. L., TAVARES, R. P., Simulação Numérica do Sopro de Oxigênio através de Bocal Supersônico. Revista Tecnologia em Metalurgia, Materiais e Mineração v. 9, n.1, jan.-mar. 2012.

6. MAIA, B. T.; SANTOS, B. O. A., GARAJAU, F. S., GUERRA, M. S. L., CFD SIMULATIONS FOR WATER FLOW IN LANCE TO BOF, $45^{\circ}$ Seminário de Aciaria Internacional. Porto Alegre, May 2014. 